\title{
HOXC10 overexpression promotes cell proliferation and migration in gastric cancer
}

\author{
JINA KIM ${ }^{1,2}$, DONG-HYUCK BAE ${ }^{1,3}$, JONG HWAN KIM ${ }^{2}$, KYU-SANG SONG ${ }^{4}$, \\ YONG SUNG KIM ${ }^{1,3}$ and SEON-YOUNG KIM ${ }^{1,2}$
}

\begin{abstract}
${ }^{1}$ Department of Functional Genomics, KRIBB School of Bioscience, Korea University of Science and Technology (UST), Yuseong-gu, Daejeon 34113; ${ }^{2}$ Personalized Genomic Medicine Research Center, Korea Research Institute of Bioscience and Biotechnology (KRIBB); ${ }^{3}$ Genome Editing Research Center, KRIBB, Yuseong-gu, Daejeon 34141; ${ }^{4}$ Department of Pathology, College of Medicine, Chungnam National University, Yuseong-gu, Daejeon 35015, Republic of Korea
\end{abstract}

Received January 4, 2019; Accepted May 14, 2019

DOI: 10.3892/or.2019.7164

\begin{abstract}
Homeodomain-containing gene 10 (HOXC10) is a member of the homeobox transcription factors that plays an important role in the development of multicellular organisms. HOXC1O is overexpressed in a variety of human cancers, and recent studies have revealed that $\mathrm{HOXC10}$ is upregulated in gastric cancer as well. However, its mechanism of action is not fully understood, thus, the role of $\mathrm{HOXC1O}$ was investigated in the present study in human gastric cancer. First, HOXC10 expression was revealed to be significantly increased in gastric cancer tissues compared to normal tissues (TCGA dataset), and HOXC10 upregulation was associated with decreased recurrence-free survival in gastric cancer patients in a public gene expression dataset. HOXC10 promoted cell proliferation and metastasis in two gastric cancer cell lines (AGS and MKN74). Analyzing TCGA 450K DNA methylation dataset, it was revealed that $\mathrm{HOXC10} \mathrm{CpG}$ sites were hypomethylated in gastric cancer tissues. Bisulfite sequencing revealed that $\mathrm{CpG}$ sites in the $\mathrm{HOXClO}$ first intronic region were hypomethylated in three gastric cancer tissues, and $\mathrm{HOXC10}$ expression was increased in gastric cancer cell lines (AGS and SNU620) in response to 5-azacytidine treatment. By RNA-sequencing of AGS cells with ectopic HOXC10 expression, it was revealed that many genes were upregulated by $\mathrm{HOXC10}$ overexpression. Among them, $C S T 1$ was predicted to be a $\mathrm{HOXC1O}$ direct target gene via prediction of $\mathrm{HOXC1O}$ binding sites from the JASPAR database. A chromatin immunoprecipitation assay revealed that $H O X C 10$ directly bound to CSTI promoter regions. The present study proposes $\mathrm{HOXC1O}$ is a potential
\end{abstract}

Correspondence to: Dr Seon-Young Kim, Department of Functional Genomics, KRIBB School of Bioscience, Korea University of Science and Technology (UST), 217 Gajeong-ro, Yuseong-gu, Daejeon 34113, Republic of Korea

E-mail: kimsy@kribb.re.kr

Key words: HOXC10, CST1, gastric cancer, DNA methylation, RNA-sequencing, chromatin immunoprecipitation prognostic marker or therapeutic target in human gastric cancer.

\section{Introduction}

Gastric cancer is one of the most frequent causes of cancer-related deaths worldwide (1) and is the most commonly diagnosed cancer, ranking third in cancer mortality rates in Korea (2). Early diagnosis, improved nutritional care, and new chemotherapies have led to better outcomes over the past 20 years (3). However, chemotherapy has limited effects (4), and targeted therapy is used only for a small subset of patients due to restricted availability of biomarkers $(5,6)$. Thus, studies of mechanisms contributing to gastric cancer are essential for development of new therapeutic strategies.

HOXC10 is a member of the HOX genes and contributes to hind limb development (7). In addition to its role as a developmental regulator, recent studies revealed additional roles of HOXC10, such as controlling the browning of white adipose tissues and regulation of the cell cycle $(8,9)$. In addition, recent studies have reported aberrant expression of $\mathrm{HOXC1O}$ and its effects in diverse cancers. Studies in glioma, lung adenocarcinoma, osteosarcoma, and thyroid cancer demonstrated that aberrant $\mathrm{HOXC10}$ expression was correlated with poor survival outcome (10-13). HOXC10 knockdown enhanced apoptosis and attenuated proliferation, metastasis, and expression of immunosuppressive genes in glioma (12). In thyroid cancer, $\mathrm{HOXC10}$ knockdown was associated with cell cycle arrest and repression of metastasis (10). In breast cancer, HOXC10 was upregulated by estrogen, which recruits MLL3 and MLL4 to the estrogen response element in the HOXC10 promoter region (14). However, in breast cancer treated with aromatase inhibitors, resistance to the inhibitors occurred through downregulation of $\mathrm{HOXC1O}$ expression mediated by hypermethylation of $\mathrm{HOXC10}$ promoter regions (15). Another study revealed that $\mathrm{HOXC10}$ contributed to chemotherapy resistance through DNA repair by binding with cyclin-dependent kinase 7 and activating the NF- $\mathrm{BB}$ pathway (16). Collectively, HOXC10 plays roles as a transcription factor in the development and in cancer progression. Moreover, HOXC10 mediates additional functions by binding to other proteins. 
Epigenetic alterations, including DNA methylation, histone modification and non-coding RNAs, are as important as genetic mutations in cancer progression and metastasis (17). DNA methylation of promoter $\mathrm{CpG}$ islands interrupts binding of transcription factors, thus, repressing gene expression (18). In cancer, numerous tumor suppressor genes are downregulated by hypermethylation, while oncogenes are upregulated by hypomethylation, at their $\mathrm{CpG}$ promoter sites $(17,18)$.

Recent studies have reported that $\mathrm{HOXC10}$ is upregulated in gastric cancer and promotes cell growth and metastasis through the MAPK (19) or NF- $\mathrm{kB}$ pathway (20). However, genetic or epigenetic changes associated with $\mathrm{HOXC10}$ overexpression in gastric cancer have yet to be identified. In addition, the target genes transcriptionally regulated by $\mathrm{HOXC10}$ overexpression are not fully understood. The aim of the present study was to investigate the epigenetic and transcriptomic alterations associated with $\mathrm{HOXC10}$ overexpression. $\mathrm{HOXC10}$ expression in gastric cancer tissues and tumorigenicity of $\mathrm{HOXClO}$ in vitro were examined. Furthermore, it was revealed that the upregulation of $\mathrm{HOXC10}$ was regulated by DNA methylation of its promoter region. Several genes transcriptionally regulated by HOXC10 were also identified.

\section{Materials and methods}

Public data analysis. Gene expression and DNA methylation data for gastric cancer patients were obtained from the GDC data portal (https://portal.gdc.cancer.gov/). Gene expression data for gastric cancer patients with survival information was downloaded from the GEO database (GSE26253) (21).

Clinical samples. Paired gastric tumor and normal tissue samples $(n=242)$ were collected from Chungnam National University Hospital (CNUH; Daejeon, Korea) with informed consent obtained from all patients and among them 171 samples have clinicopathological information. The present study was approved by the Internal Review Board of CNUH.

Cell culture, transfection and 5-aza-2'-deoxycitidine (5-aza-dC) treatment. Gastric cancer cell lines (SNU-001, SNU-005, SNU-216, SNU-016, SNU-484, SNU-520, SNU-601, SNU-620, SNU-638, SNU-668, SNU-719, AGS, KATOIII, MKN1, MKN45 and MKN74) were obtained from the Korean Cell Line Bank (http://cellbank.snu.ac.kr/main/index.html) and were maintained in complete RPMI-1640 and DMEM medium (Welgene, Inc., Gyeongsan-si, Korea) at $37^{\circ} \mathrm{C}$ in a humidified $5 \% \mathrm{CO}_{2}$ incubator. Complete media were supplemented with $10 \%$ fetal bovine serum (FBS; Welgene, Inc.) and $1 \%$ antibiotic-antimycotic solution (Gibco; Thermo Fisher Scientific, Inc., Waltham, MA, USA). The HOXC10 full cDNA clone was amplified by RT-PCR (primer sequences are listed in Table SI) and inserted into the pCDH-CMV-MCS-EF1-Puro (CD510B-1) lentiviral vector. An empty vector was used as a control. For viral particle generation, cloned DNAs and lentiviral packaging Mix (Sigma-Aldrich; Merck KGaA, Darmstadt, Germany) were transfected into 293T cells using X-tremeGENE ${ }^{\mathrm{TM}}$ HP DNA Transfection reagent (Roche Diagnostics, Basel, Switzerland) in Opti-MEM media (Gibco; Thermo Fisher Scientific, Inc.). After $2 \mathrm{~h}$ of incubation, the media was changed to complete media. After $48 \mathrm{~h}$ of incubation, virus particles were collected from the supernatant. For viral infection, $2 \times 10^{5}$ gastric cancer cells were added to each well of a 6-well plate and incubated overnight at $37^{\circ} \mathrm{C}$. Viral supernatant was added to plated cells, and after incubation for overnight at $37^{\circ} \mathrm{C}$, the media was changed to complete media. After $24 \mathrm{~h}$, infected cells were selected using puromycin treatment. HOXC10 transfection was confirmed by RT-PCR and western blot analysis. The siRNA in this study was purchased from Bioneer Corp. (Daejeon, Korea). The antisense and sense sequences of the siRNA are the following. siCST1: CUAUAACGCAGACCUCAAU and AUUGAGGUC UGCGUUAUAG. A total of $100 \mathrm{nM}$ siRNA was transfected with the Lipofectamine RNAiMAX reagent (Invitrogen; Thermo Fisher Scientific, Inc.) according to the manufacturer's instructions. One million cells were treated with $10 \mu \mathrm{M}$ 5-aza-dC (Sigma-Aldrich; Merck KGaA) in a $100-\mathrm{mm}$ dish for three days with media changes every $24 \mathrm{~h}$ following by harvesting.

Reverse transcription PCR, quantitative real-time PCR and western blot analysis. Total RNA was extracted using the RNeasy Plus Mini kit (Qiagen, Venlo, The Netherlands) according to the manufacturer's instructions. Reverse transcription was performed using $1 \mu \mathrm{g}$ total RNA as the template and iScript cDNA Synthesis kit (Bio-Rad Laboratories, Hercules, CA, USA). RT-PCR assays were performed using a PCR Master Mix (MGmed, Inc., Seoul, Korea) for $5 \mathrm{~min}$ at $25^{\circ} \mathrm{C}$, for $30 \mathrm{~min}$ at $42^{\circ} \mathrm{C}$, for $5 \mathrm{~min}$ at $85^{\circ} \mathrm{C}$. Quantitative real-time PCR (qPCR) reactions were performed in triplicate on a CFX96 ${ }^{\mathrm{TM}}$ Real-Time PCR Detection System (Bio-Rad Laboratories) using SsoAdvanced ${ }^{\mathrm{TM}}$ Universal Inhibitor-Tolerant SYBR-Green Supermix (Bio-Rad Laboratories) for $3 \mathrm{~min}$ at $95^{\circ} \mathrm{C}$, and 40 cycles for $20 \mathrm{sec}$ at $95^{\circ} \mathrm{C}$, for $20 \mathrm{sec}$ at $60^{\circ} \mathrm{C}, 20 \mathrm{sec} 72^{\circ} \mathrm{C}$. The relative expression of cDNA was normalized to $\beta$-actin, quantified using the $2^{-\Delta \Delta \mathrm{Cq}}$ cycle threshold method (22), and at least three independent biological replicates were included for each reaction. Primers used for PCR were designed either manually or using the Primer3 program (http://bioinfo.ut.ee/primer3-0.4.0/). All primer sequences are listed in Table SI. Cells were lysed using 2X Laemmli sample buffer [4\% SDS, 20\% glycerol, $120 \mathrm{mM}$ Tris-Cl (pH 6.8)] with a protease inhibitor cocktail (Roche Diagnostics). Supernatants were collected and quantified using bovine serum albumin (BSA) (Thermo Fisher Scientific, Inc.) by Bradford assay. A total of $30 \mu \mathrm{g}$ proteins were loaded onto $12 \%$ polyacrylamide gels, electrophoresed and transferred to a polyvinylidene difluoride (PVDF) membrane (Roche Diagnostics) and probed with the HOXC10 antibody (dilution 1:1,000; rabbit polyclonal; cat. no. ab153904; Abcam, Cambridge, MA, USA) and $\beta$-actin antibody (dilution 1:1,000; mouse monoclonal; cat no. 061M4808; Sigma-Aldrich) at $4^{\circ} \mathrm{C}$ overnight. HRP-conjugated anti-rabbit and anti-mouse IgG antibodies (dilution 1:5,000; cat. nos. sc-2357 and sc-516102; Santa Cruz Biotechnology, Inc., Dallas, TX, USA) were used as the secondary antibody at room temperature for $2 \mathrm{~h}$. Bands were detected with ECL reagent (Amersham Biosciences, Buckinghamshire, UK) and scanned with a Fujifilm LAS-4000 Imaging System and analyzed using MultiGauge Software (Fujifilm, Brookvale, Australia). 
Cell proliferation, colony formation, migration and wound healing assays. Suspensions of $1.0 \times 10^{3}$ cells were seeded into 96-well plates. After $24,48,72$ or $96 \mathrm{~h}$ of incubation at $37^{\circ} \mathrm{C}$, EZ-cytox Cell Viability Assay kit mixture (DoGen, Seoul, Korea) was added. After $1 \mathrm{~h}$ of incubation, the fluorescence intensity ratio from 650 to $450 \mathrm{~nm}$ was measured. Suspended AGS $\left(1 \times 10^{3}\right)$ cells were added to each well of a 6 -well plate and incubated at $37^{\circ} \mathrm{C}$ for seven days. Colony forming cells were stained using $0.5 \%$ crystal violet staining solution (Sigma-Aldrich; Merck KGaA) and counted. Transwell chambers (Corning Inc., Corning, NY, USA) were coated with fibronectin (Sigma-Aldrich; Merck KGaA). Cells were suspended in serum-free media and seeded into the upper chamber at a density of $1 \times 10^{5}$ cells (MKN74) and $1.5 \times 10^{4}$ cells (AGS) per well, and serum-containing media was placed into the lower chamber. After incubation at $37^{\circ} \mathrm{C}$ for $18-20 \mathrm{~h}$, cells penetrating the pores were stained using $0.5 \%$ crystal violet staining solution (Sigma-Aldrich; Merck $\mathrm{KGaA}$ ) and observed under a light microscope. Suspended MKN74 cells $\left(5 \times 10^{4}\right)$ were plated into each well of Culture-Insert 2 Well in $\mu$-Dish $35 \mathrm{~mm}$ (ibidi Gmbh, Martinsried, Germany). After $24 \mathrm{~h}$ of incubation at $37^{\circ} \mathrm{C}$, cells were gently removed from the Culture-Insert using sterile tweezers. The used dish was filled with cell-free medium and observed after 24, 48 and $72 \mathrm{~h}$ under a light microscope.

Bisulfite sequencing. Genomic DNA was bisulfite modified using the EZ DNA methylation kit (Zymo Research, Irvine, CA, USA) and PCR amplified. PCR products were cloned into a pGEM-T Easy vector (Promega, Madison, WI, USA) and a few clones were randomly selected for sequencing. Bisulfite-modified DNA was amplified using a primer set designed to amplify a site between +832 and +1176 relative to the transcription start site using MethPrimer (http://www. urogene.org/cgi-bin/methprimer/meth-primer.cgi). Primer sequences were 5'-GGGTAAAGTGAGTTTTTTTGAGAT TTTTAA-3' (forward) and 5'-CTTCCCTAATCCCTAACC CAAAATC-3' (reverse). Methylation levels are indicated as the percentage of $\mathrm{CpG}$ methylated sites among all $\mathrm{CpG}$ sites.

RNA sequencing and data access. The RNA sequencing library was prepared using the TruSeq RNA Sample Prep kit (Illumina, San Diego, CA, USA; https://www.illumina. com), and sequencing was performed using the Illumina HiSeq 2000 platform to generate 100 -bp paired-end reads. Sequenced reads were mapped to the human genome (hg19) using STAR (v.2.5.1), and gene expression levels were quantified with the count module in STAR (23). The TMM (trimmed mean of M-values)-normalized CPM (counts per million) value of each gene was set to a baseline of 1 and $\log _{2}$-transformed for further analysis (i.e., clustering, heat map drawing and correlation analysis). NGS data were deposited in the NCBI Gene Expression Omnibus (GEO) under the accession no. GSE119196. Raw sequence tags were deposited in the NCBI Short Read Archive (SRA) under the accession no. SRP159087.

Chromatin immunoprecipitation assay. Chromatin immunoprecipitation (ChIP) was performed using Dynabeads Protein A and G (Thermo Fisher Scientific, Inc.). For ChIP-PCR/qPCR, $2.0 \times 10^{7}$ cells were cross-linked with
$1 \%$ formaldehyde for $10 \mathrm{~min}$ at $25^{\circ} \mathrm{C}$. Cells were then resuspended and lysed for $10 \mathrm{~min}$ at $4^{\circ} \mathrm{C}$ with SDS lysis buffer. The lysate was aliquoted into a milliTUBE $1 \mathrm{ml}$ AFA Fiber (Covaris, Inc., Woburn, MA, USA) and sonicated using a M220 Focused-ultrasonicator (Covaris, Inc.). Fragment sizes were $200-500 \mathrm{bp}$. Samples were diluted with low-salt RIPA buffer and pre-cleared with $50 \mu \mathrm{l}$ of Dynabeads Protein A and $\mathrm{G}$ for $1 \mathrm{~h}$ at $4^{\circ} \mathrm{C}$. Primary antibodies were added to pre-cleared supernatants, and the mixtures were incubated overnight at $4^{\circ} \mathrm{C}$. Antibodies used for the ChIP assay include HOXC10 (dilution 1:400; rabbit polyclonal; cat. no. ab153904; Abcam), phosphorylated RNA polymerase II (dilution 1:400; mouse monoclonal; cat. no. ab5408; Abcam), and IgG antibodies (dilution 1:1,000; cat. nos. sc-2357 and sc-516102; Santa Cruz Biotechnology, Inc.). Next, $50 \mu 1$ Dynabeads Protein $\mathrm{A}$ and $\mathrm{G}$ were added to the samples, and the mixtures were incubated for $2 \mathrm{~h}$ at $4^{\circ} \mathrm{C}$. The beads were subsequently washed with wash buffer (low-salt RIPA, high-salt RIPA, LiCl and TE). Precipitated chromatin was eluted in $200 \mu 1$ elution buffer (0.1 M NaHCO3 and 1\% SDS). Reverse cross-linking was performed overnight at $65^{\circ} \mathrm{C}$, and chromatin was then treated with RNase A and $5 \mathrm{M} \mathrm{NaCl}$ for $30 \mathrm{~min}$ at $37^{\circ} \mathrm{C}$ and proteinase $\mathrm{K}$ overnight at $65^{\circ} \mathrm{C}$. DNA was purified using a QIAquick PCR Purification kit (Qiagen). ChIP-PCR assays were performed using PCR Master Mix and electrophoresis $1 \%$ agarose gel. ChIP-qPCR reactions were subsequently performed.

Statistical analysis. All experiments were triplicated and data are indicated as mean \pm standard deviation. Statistical analysis was performed using Student's t-test. A P-value $<0.05$ was considered significant. The following parameters were obtained from the medical records of the 171 patients included in the study: Age, sex, histology, lymph node metastasis, tumor stage, and Helicobacter pylori infection status, and these parameters were compared using a Chi-square test. Statistical analysis of correlation between expression and methylation was performed using Pearson's correlation coefficient. All statistical analysis were performed using $\mathrm{R}$ statistical programming language (version 3.4.2; https://www.r-project.org/).

\section{Results}

HOXC10 is overexpressed and associated with poor prognosis in gastric cancer tissues. HOXC10 is upregulated in many types of cancer. To investigate whether HOXC10 is overexpressed in gastric cancer tissues, we used TCGA-STAD RNA-Sequencing expression dataset. HOXC10 expression was revealed to be higher in gastric cancer tissues than in normal tissues in TCGA dataset (Fig. 1A). The relationship between HOXC10 expression and recurrence-free survival was then investigated in gastric cancer patients from the GEO dataset (GSE26253), demonstrating that the HOXC10 high-expression group exhibited decreased recurrence-free survival compared to the HOXC10 low-expression group from the GEO dataset (Fig. 1B). Overexpression of HOXC10 was validated by performing RT-qPCR on paired normal and tumor tissue samples collected from CNUH (Fig. 1C). Clinicopathological characteristics with respect to HOXC10 expression from the CNUH dataset are summarized in Table I. A significant 
A

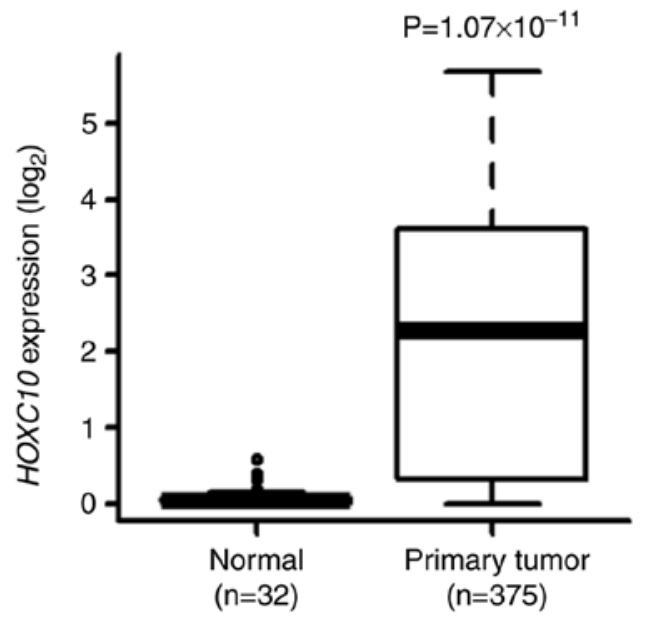

B

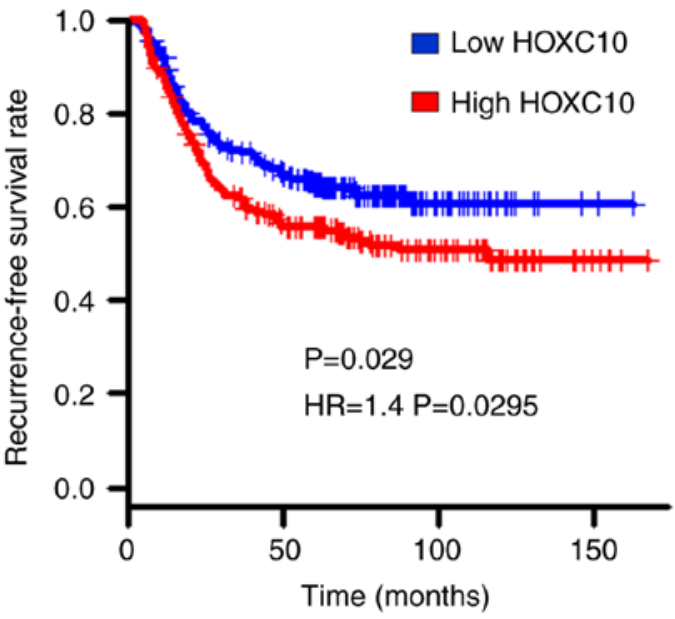

C

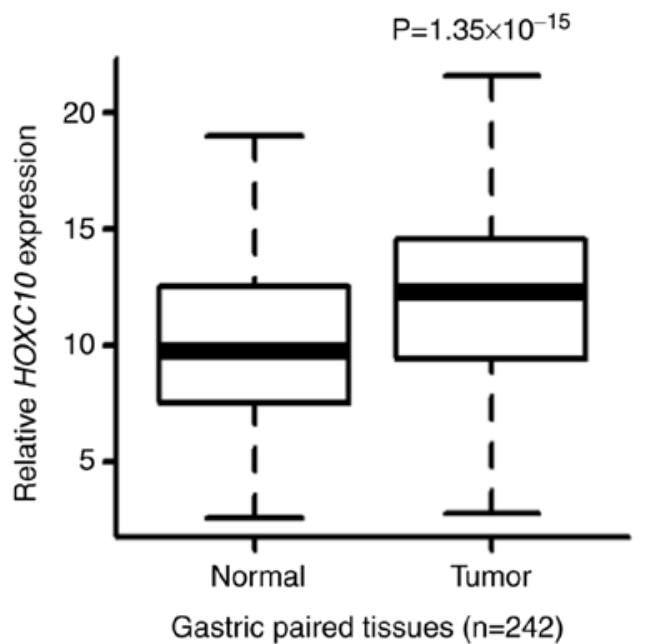

Figure 1. HOXC10 overexpression promotes gastric cancer progression. (A) Comparison of $\mathrm{HOXC10}$ expression between normal and tumor gastric tissues (TCGA datasets). (B) Kaplan-Meyer plot of two groups of gastric cancer patients classified by HOXC10 expression (GSE26253. N=432 $\mathrm{P}=0.029, \log$-rank test; Hazard ratio $=1.4, \mathrm{P}=0.0295$, cox-regression test). Red, high-expression group; blue, low-expression group. (C) Relative HOXC10 mRNA levels in paired tumor and normal gastric tissues collected at CNUH by RT-qPCR. HOXC10, homeodomain-containing gene 10; $\mathrm{CNUH}$, Chungnam National University Hospital.

difference in $\mathrm{HOXC10}$ expression was observed between diffuse and intestinal cancer types $(\mathrm{P}=0.039)$, but there was no significant difference in other parameters.
Table I. Clinicopathological characteristics by HOXC10 expression in gastric cancer patients.

\begin{tabular}{|c|c|c|c|}
\hline \multirow[b]{2}{*}{$\begin{array}{l}\text { Clinicopathological } \\
\text { parameters }\end{array}$} & \multicolumn{2}{|c|}{$\begin{array}{l}\text { Gastric tumors with } \\
\text { increased relative } \\
\text { HOXC10 expression }\end{array}$} & \multirow[b]{2}{*}{ P-value } \\
\hline & $\begin{array}{c}>2 \text {-Fold } \\
\text { increase } \\
(\mathrm{n}=98)\end{array}$ & $\begin{array}{c}\leq 2 \text {-Fold } \\
\text { increase } \\
(\mathrm{n}=73)\end{array}$ & \\
\hline $\begin{array}{l}\text { Mean patient age } \\
\text { (in years } \pm \text { SD) }\end{array}$ & $60 \pm 12$ & $59 \pm 14$ & 0.9270 \\
\hline Sex & & & 0.4769 \\
\hline Male & 62 & 50 & \\
\hline Female & 36 & 23 & \\
\hline Lauren's classification & & & $0.0386^{\mathrm{a}}$ \\
\hline Intestinal & 23 & 26 & \\
\hline Diffuse & 69 & 38 & \\
\hline Mixed & 6 & 8 & \\
\hline No information & 0 & 1 & \\
\hline Tumor progression & & & 0.8769 \\
\hline EGC & 10 & 7 & \\
\hline AGC & 87 & 66 & \\
\hline No information & 1 & 0 & \\
\hline Stage & & & 0.4522 \\
\hline I & 17 & 15 & \\
\hline II & 23 & 19 & \\
\hline III & 27 & 21 & \\
\hline IV & 31 & 18 & \\
\hline $\begin{array}{l}\text { Helicobacter pylori } \\
\text { infection }\end{array}$ & & & 0.7343 \\
\hline Positive & 59 & 43 & \\
\hline Negative & 23 & 19 & \\
\hline No information & 16 & 18 & \\
\hline
\end{tabular}

${ }^{\mathrm{a}} \mathrm{P}<0.05 . H O X C 10$, homeodomain-containing gene 10 .

HOXC10 promotes cell proliferation and cell migration in MKN74 and AGS cell lines. The functional effects of $\mathrm{HOXC10}$ overexpression were first investigated in gastric cancer using in vitro assays. RT-PCR of HOXC10 among 16 gastric cancer cell lines illustrated that AGS and MKN74 cells expressed $\mathrm{HOXC10}$ at low levels, while SNU-216, SNU-484, KATOIII and MKN45 cells expressed HOXC10 at high levels (Fig. 2A). Thus, AGS and MKN74 cells were selected for infection with lentiviruses ectopically expressing HOXC1O. Overexpression of HOXC10 in AGS and MNK74 cells after lentivirus infection was confirmed by RT-qPCR and western blot analysis (Fig. 2B). HOXC10 overexpression increased proliferation (Fig. 2C) and colony formation (Fig. 2D) in AGS cells and increased migration in both AGS and MKN74 cells (Fig. 2E and F). Recent studies have demonstrated that overexpression of $\mathrm{HOXC10}$ promotes cell proliferation and migration in gastric cancer GC-9811P, AGS and SGC7901 cells, and HOXC10 knockdown suppresses progression of gastric 
A
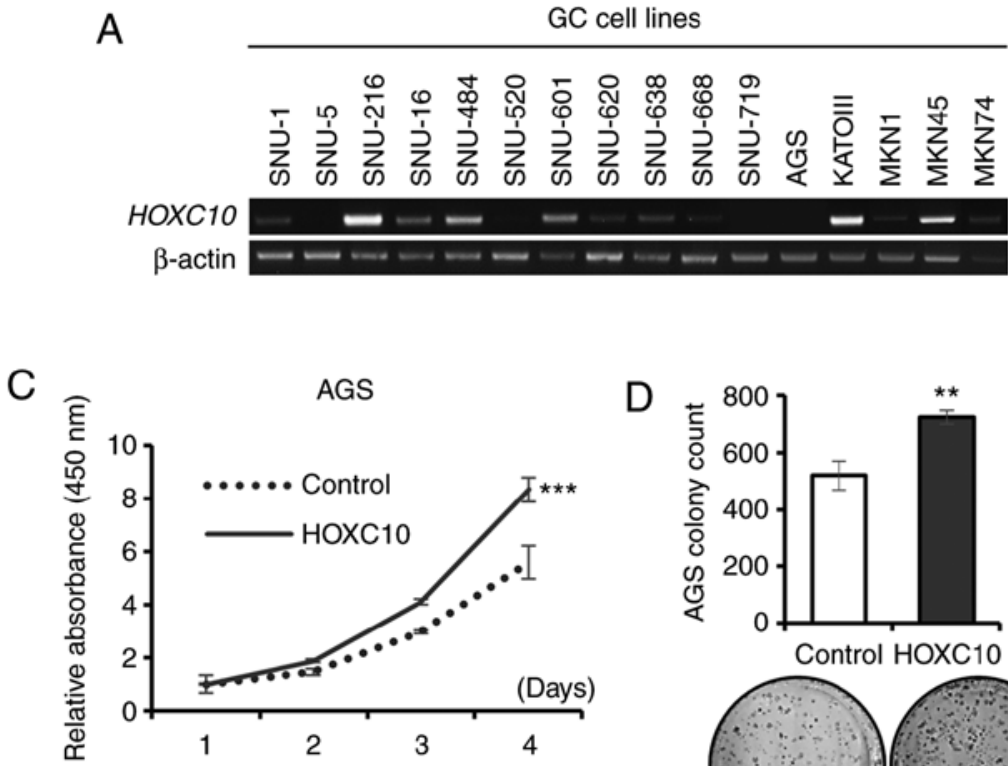

E

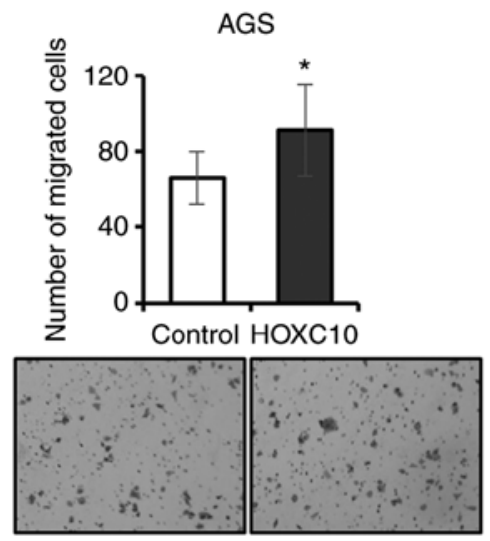

D
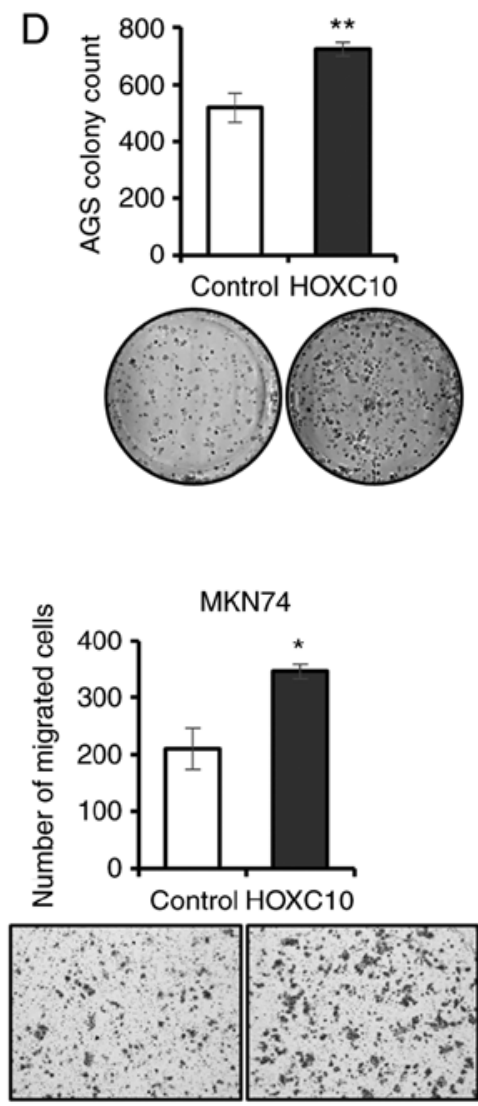

B

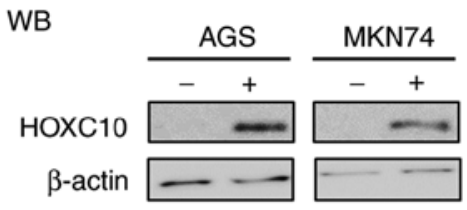

RT-qPCR

$\square$ Control $-\mathrm{HOXC10}$

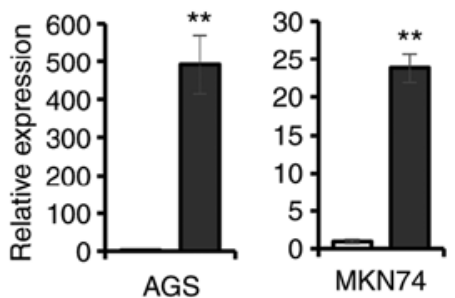

\section{$\mathrm{F}$}
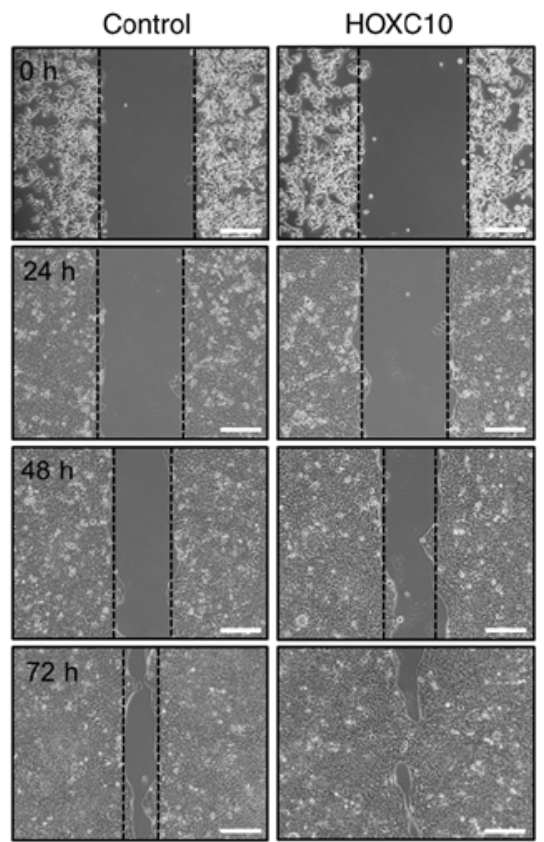

Figure 2. HOXC10 increases gastric cancer cell proliferation and migration. (A) HOXC10 mRNA expression in human gastric cancer cell lines by RT-PCR (B) RT-qPCR and western blot analysis of HOXC10 after ectopic HOXC10 overexpression in AGS and MKN74 cells. (C) Proliferation assay (CCK-8) after HOXC10 overexpression in AGS cells. (D) Colony formation assay after HOXC10 overexpression in AGS cells. (E) Migration assay after HOXC10 overexpression in AGS and MKN74 cells. (F) Wound healing assay after HOXC10 overexpression in MKN74 cells. Scale bar, $200 \mu \mathrm{m}$. For all, ${ }^{*} \mathrm{P}<0.05 ;{ }^{* *} \mathrm{P}<0.01$; ${ }^{* * * *} \mathrm{P}<0.001$, Student's t-test. The error bars represent the mean \pm SD. HOXC10, homeodomain-containing gene 10; CCK-8, Cell Counting Kit-8.

cancer in GC-9811P, SNU638 and SGC7901 cells $(19,20,24)$. A mouse model injected with AGS cells containing upregulated $\mathrm{HOXC10}$ exhibited increased tumor size (19). Collectively, it was concluded that $\mathrm{HOXC10}$ overexpression promotes proliferation, colony formation and progression in gastric cancer.

HOXC10 expression is regulated by DNA methylation in gastric cancer tissues and cells. To reveal the mechanism of HOXC10 overexpression in gastric cancer, publicly available TCGA STAD datasets were analyzed for DNA methylation and copy number alterations. For copy number alteration, the $\mathrm{HOXClO}$ gene was altered in $1.69 \%$ of 295 cases (amplification, 1.02\%; deep deletion, $0.68 \%$ ) using cBioPortal (http://www.cbioportal. org/index.do). To determine whether methylation of $\mathrm{HOXClO}$ CpG sites affected $\mathrm{HOXC10}$ expression, we analyzed TCGA
STAD $450 \mathrm{~K}$ array dataset. It was observed that many $\mathrm{CpG}$ sites in the $\mathrm{HOXC10}$ gene were hypomethylated in gastric cancer compared to normal tissues (Fig. 3A). We next attempted bisulfite sequencing to determine methylation levels of $\mathrm{HOXC10}$ $\mathrm{CpG}$ sites. In fact, reduced methylation at $24 \mathrm{CpG}$ sites of the first intronic region of $\mathrm{HOXC1O}$ (Chr12: 54,379,876-54,380,219; +832 to +1176 ) was confirmed in three gastric cancers compared to normal tissues (Fig. 3B). The region contains the promoter region (chr12:54,380,069-54,380,128; promoter ID: HOXC10_4) obtained from a Eukaryotic promoter database (https://epd.vital-it.ch/index.php). Specifically, $\mathrm{CpG}$ residues 3, $7,8,13$ and 16 were significantly hypomethylated in tumor tissues $(\mathrm{P}<0.05$, Student's t-test). By correlation analysis of DNA methylation (TCGASTAD $450 \mathrm{~K}$ array) and gene expression (TCGA STAD RNA-seq) data, it was revealed that three $\mathrm{CpG}$ sites (indicated in Fig. 3B) exhibited significant 
A
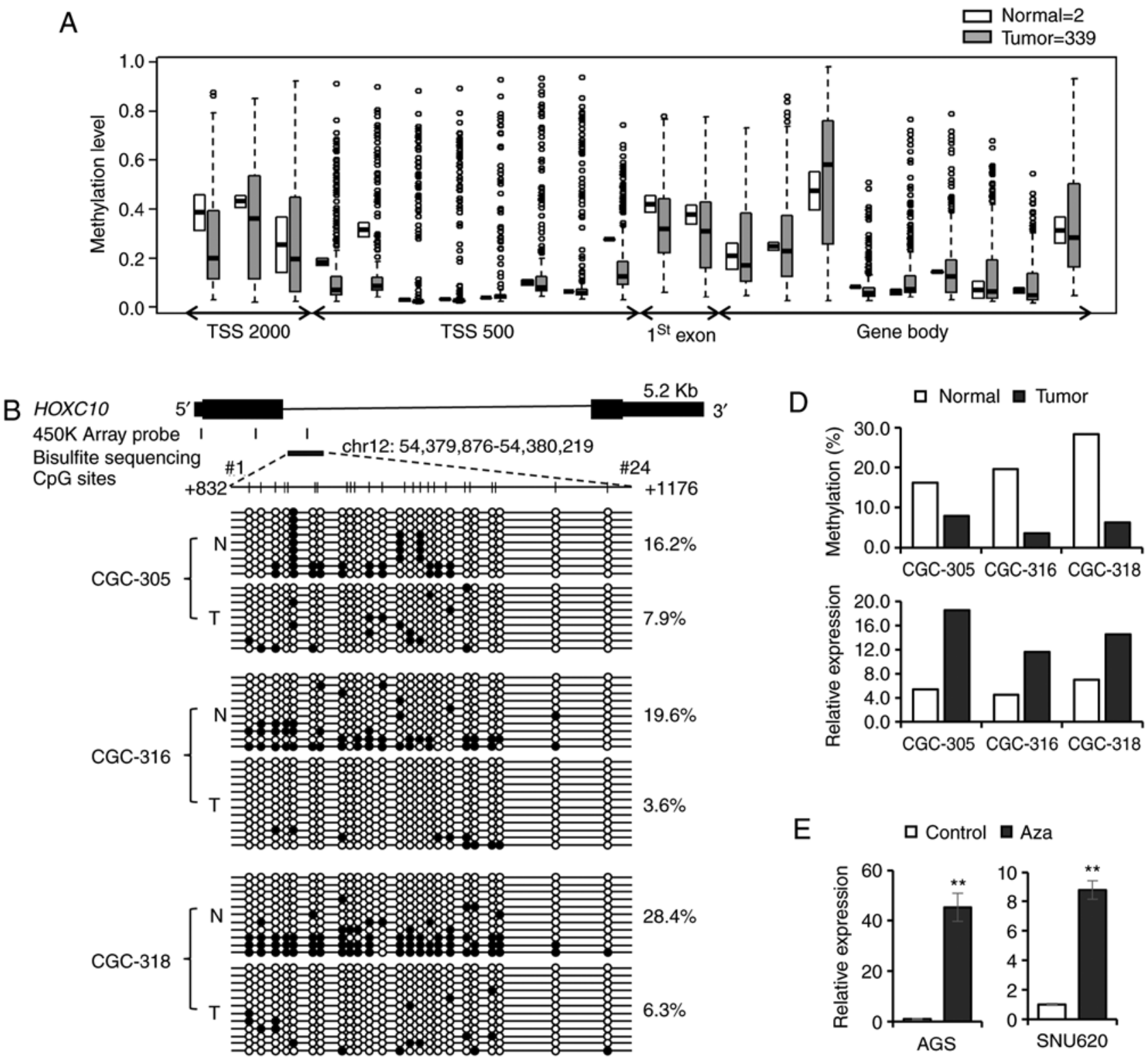

E
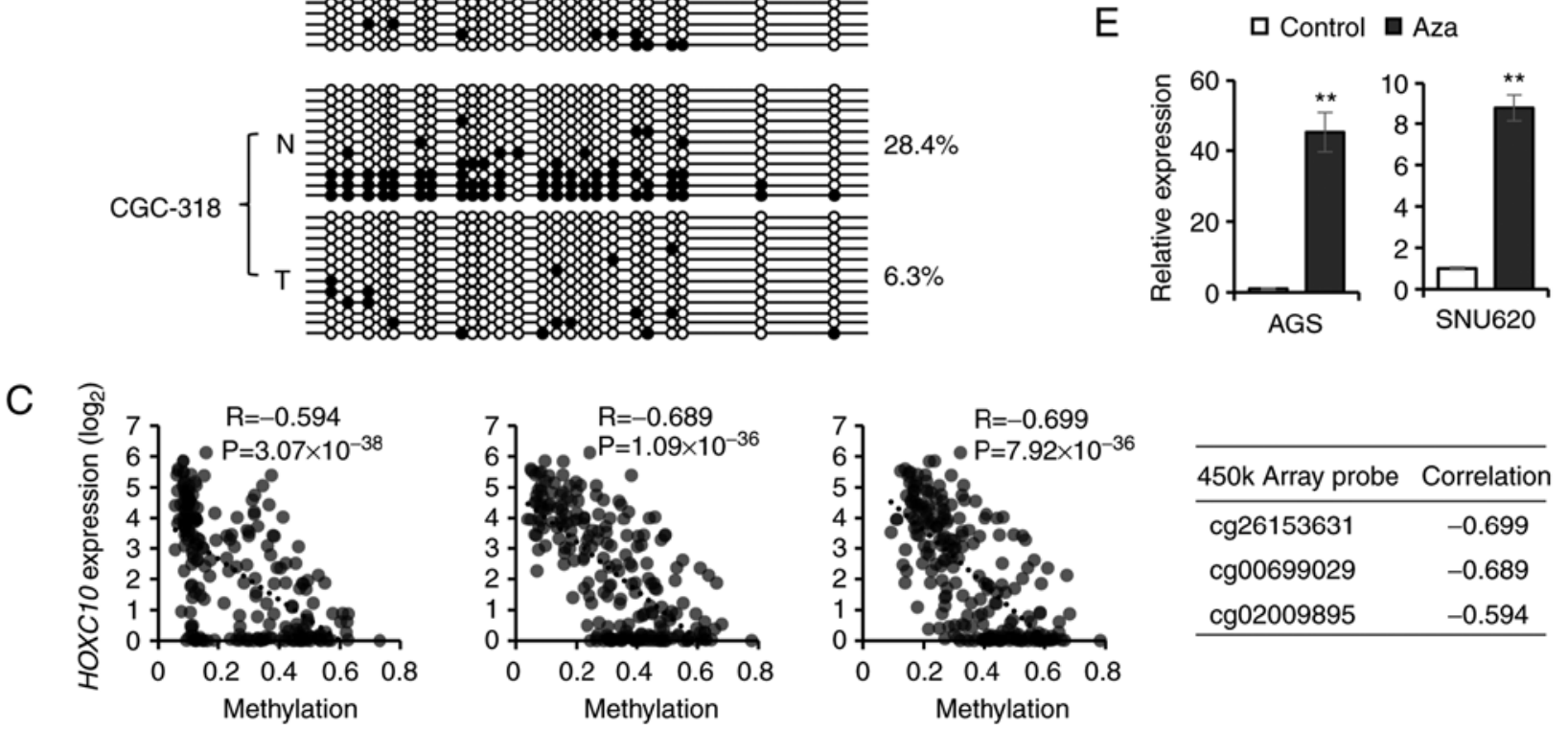

\begin{tabular}{cc}
\hline 450k Array probe & Correlation \\
\hline cg26153631 & -0.699 \\
cg00699029 & -0.689 \\
cg02009895 & -0.594 \\
\hline
\end{tabular}

Figure 3. Methylation profiling of $\mathrm{HOXC10}$ in gastric tissues and cell lines. (A) Methylation status of $\mathrm{HOXC10} \mathrm{CpG}$ sites from TCGA $450 \mathrm{~K}$ array dataset. (B) Result of bisulfite sequencing of $24 \mathrm{CpG}$ sites in the HOXC10 first intron region (N, normal tissue; T, tumor tissue). (C) Significant negative correlation between DNA methylation and mRNA expression in three CpG sites (Pearson's correlation coefficient, Student's t-test). (D) Comparison between methylation levels from bisulfite sequencing and HOXC10 expression levels in paired gastric tumor and normal tissues. (E) Restoration of $H O X C 10$ expression by 5 -azacytidine treatment in AGS and SNU-620 cells ( ${ }^{* *} \mathrm{P}<0.01$, Student's t-test. The error bars represent the mean $\pm \mathrm{SD}$ ). HOXC10, homeodomain-containing gene 10.

negative correlations between methylation of $\mathrm{HOXC10 \textrm {CpG }}$ sites and HOXC10 expression (Pearson's correlation coefficient $\mathrm{r}=-0.594,-0.689$ and -0.699 ) (Fig. 3C). The methylation levels and HOXC10 expression levels were examined in three paired gastric tumor and normal tissues (Fig. 3D). When two gastric cancer cell lines (AGS and SNU-620 with low HOXC10 expression) were treated with 5-aza-dC, an inhibitor of DNA methyltransferase, HOXC10 expression increased 45.24-fold (AGS) and 8.79-fold (SNU-620) (Fig. 3E). These results indicate that the methylation status of $\mathrm{CpG}$ sites in the HOXC10 first 


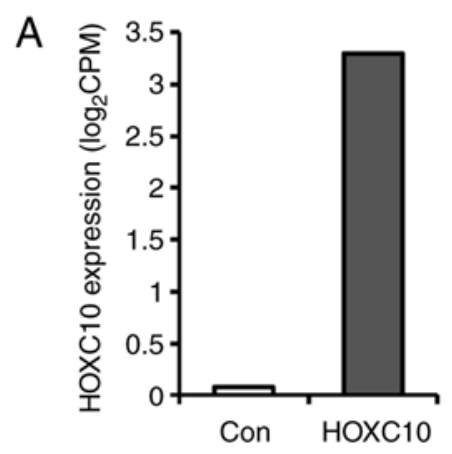

C $\mathrm{qPCR}$

B

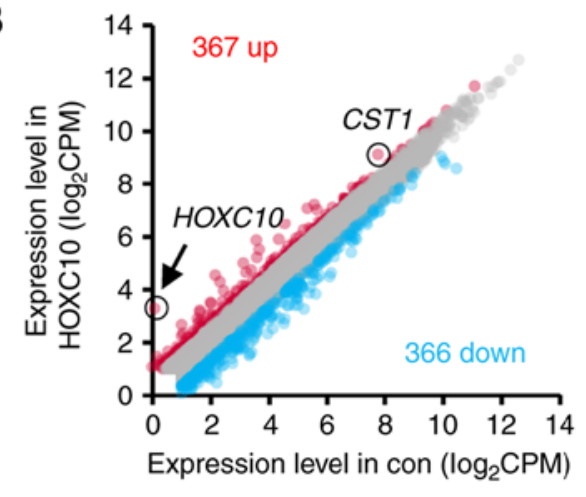

E

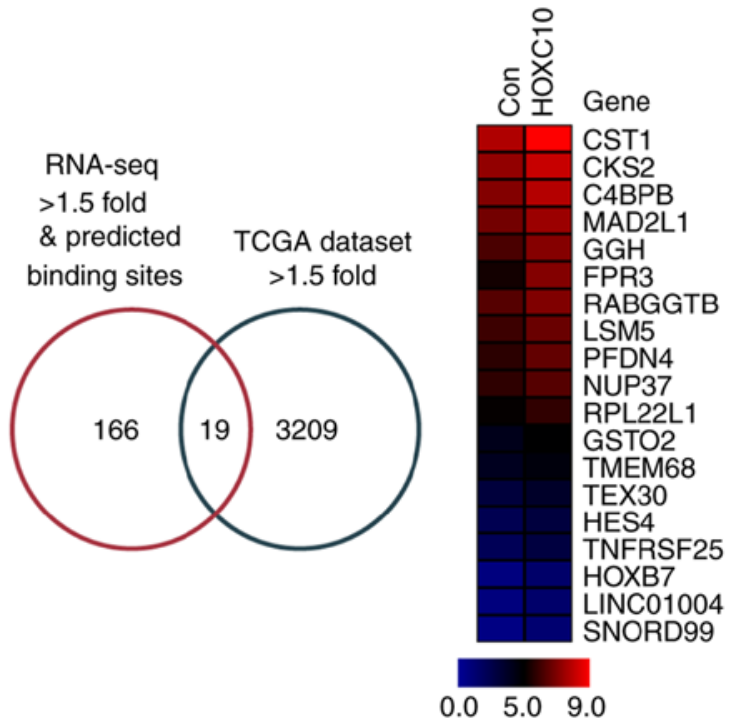

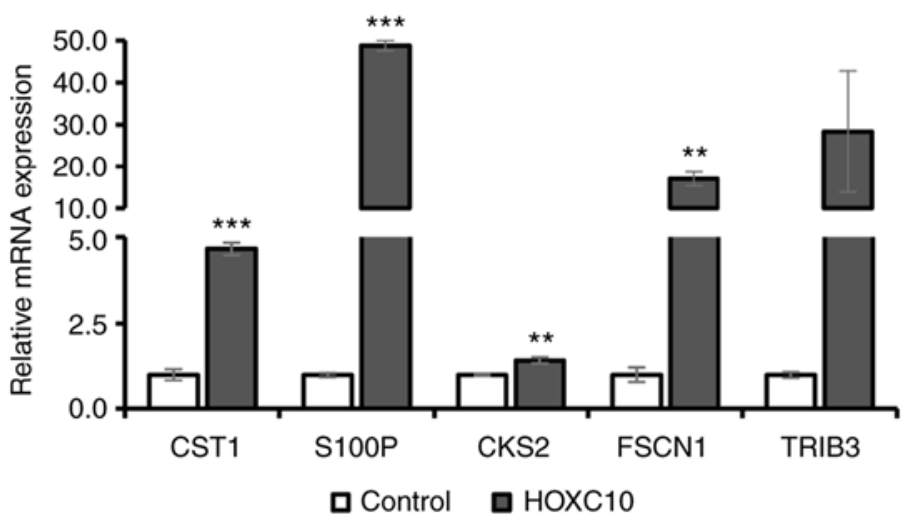

D

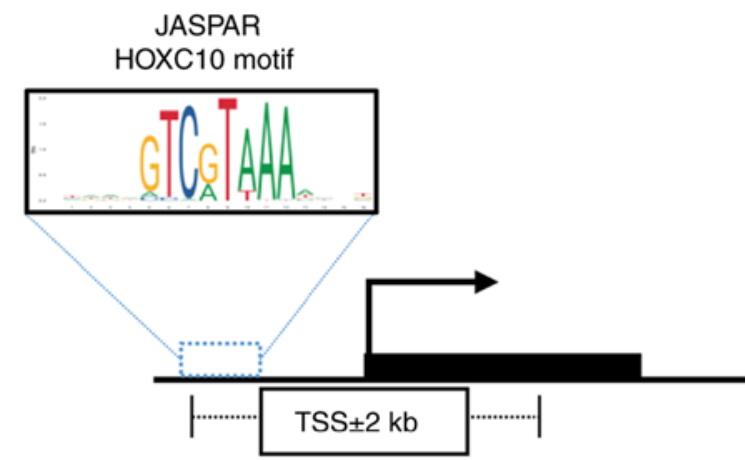

Predicted HOXC10 binding site $P$ value $<0.001$

FC

1.37

0.84

0.77

0.62

0.91

1.75

0.67

0.70

0.85

0.62

0.68

0.81

0.61

0.61

0.64

0.71

0.69

0.62

0.61

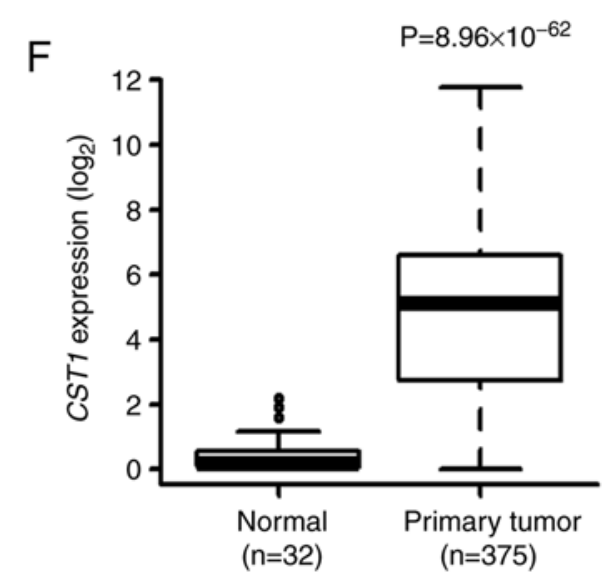

Figure 4. Selection of a direct target of HOXC10 by RNA-sequencing data analysis. (A) HOXC10 expression levels from RNA-sequencing in response to ectopic HOXC10 overexpression in AGS cells. (B) Scatter plot of expression level of 733 genes ( $\log 2 \mathrm{FCl}>1.5$ ) from RNA-seq. (C) Validation of upregulated genes in RNA-sequencing results by RT-qPCR $\left({ }^{* *} \mathrm{P}<0.01,{ }^{* * *} \mathrm{P}<0.001\right.$; Student's $t$-test. The error bars represent the mean \pm SD). (D) Predicted HOXC10 binding motif site sequence from the database JASPAR. (E) Predicted target genes via RNA-sequencing, predicted binding sites and TCGA expression dataset. (F) Comparison of CST1 expression in normal and tumor gastric tissues (TCGA datasets). HOXC10, homeodomain-containing gene 10.

intronic region was important for the regulation of $\mathrm{HOXC10}$ expression in gastric cancer.

Transcription factor HOXC10 promotes CSTI transcription. It was demonstrated that $\mathrm{HOXC10}$ was upregulated by hypomethylation of its $\mathrm{CpG}$ sites, and $\mathrm{HOXC1O}$ overexpression contributed to the progression of gastric cancer. Since HOXC10 is a transcription factor, the functional roles of $\mathrm{HOXC1O}$ overexpression were further explored in gastric cancer by identifying its target genes. Hence, RNA sequencing of ectopic HOXC10-overexpressing AGS cells was performed to identify target genes regulated by HOXC10. RNA-sequencing analysis confirmed overexpression of HOXC10 in AGS cells (3.21-fold increase compared to control vector-infected cells; Fig. 4A). 
A $<$ CST1 promoter $>$

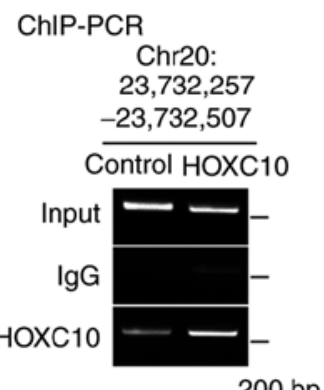

$200 \mathrm{bp}$

C <S100P promoter>

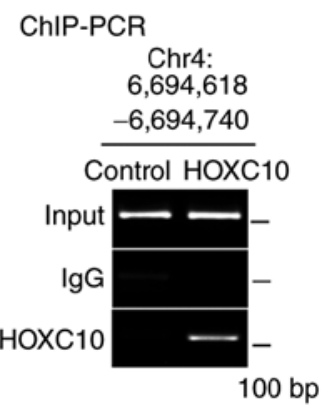

ChIP-qPCR

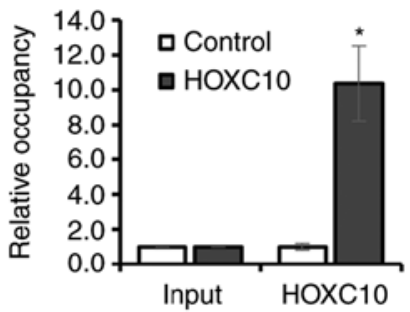

ChIP-qPCR

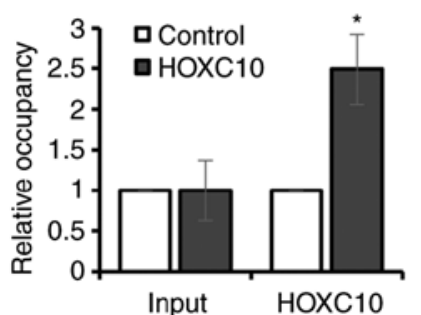

B

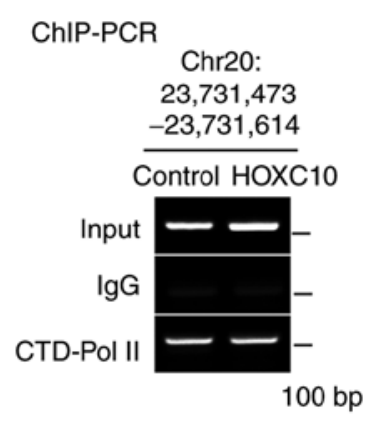

LS10OPTSS>

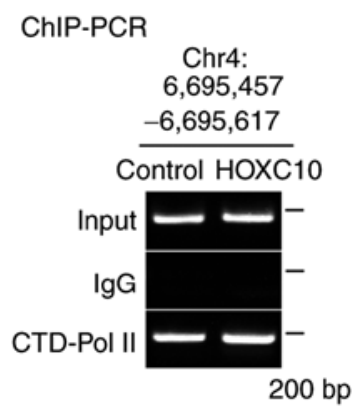

ChIP-qPCR

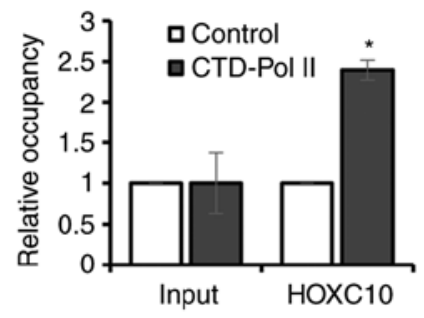

ChIP-qPCR

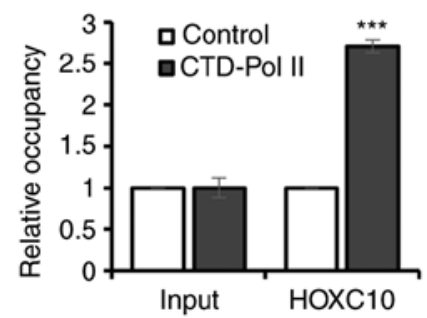

Figure 5. Validation of CST1 and S100P as direct target genes of HOXC10. (A) Ascertainment of HOXC10 binding to the CST1 promoter region (Chr20:23,732,257-23,732,507) using ChIP-PCR and ChIP-qPCR. (B) Ascertainment of phosphorylated RNA polymerase II (phospho-Ser5) binding to the CST1 TSS region (Chr20: 23,731,473-23,731,614) using ChIP-PCR and ChIP-qPCR. (C) Ascertainment of HOXC10 binding to the S100P promoter region $(6,694,618-6,694,740)$ using ChIP-PCR and ChIP-qPCR. (D) Ascertainment of phosphorylated RNA polymerase II (phospho-Ser5) binding to the S100P TSS region (Chr4: 6,695,457-6,695,617) using ChIP-PCR and ChIP-qPCR. For all, ${ }^{*} \mathrm{P}<0.05 ;{ }^{* * *} \mathrm{P}<0.001$, Student's t-test. The error bars represent the mean $\pm \mathrm{SD}$. HOXC10, homeodomain-containing gene 10 .

Three hundred and sixty-seven (upregulated) and 366 (downregulated) genes were differentially expressed in response to ectopic $\mathrm{HOXC10}$ expression [ $\left[\log _{2}\right.$ (fold-change)! >1.5; Fig. 4B and Table SII]. Five of the highly upregulated genes (CST1, S100P, CKS2, FSCN1 and TRIB3) were validated in $\mathrm{HOXC10}$-overexpressing cells compared to controls by RT-qPCR (Fig. 4C). The HOXC10 binding motif sequence predicted by the JASPAR database (http://jaspar.genereg.net/) was mapped to predicted promoter regions $(\mathrm{TSS} \pm 2 \mathrm{~kb})$ of RNA-seq fold-change $>1.5$ genes, and 185 genes were selected ( $\mathrm{P}<0.001)$ (Fig. 4D and Table SIII). By combining two different data sets (RNA-seq fold-change $>1.5$ with binding motif of HOXC10 predicted by JASPAR database, and gene expression increased >1.5-fold in TCGA dataset), 19 genes were selected as potential target genes regulated by HOXC10 (Fig. 4E). For example, CSTI expression was significantly overexpressed in TCGA dataset (Fig. 4F). A recent study reported that CSTI is upregulated and promotes cell proliferation in gastric cancer (25).

Chromatin immunoprecipitation (ChIP) was then performed in cells with ectopic HOXC1O expression. First, a ChIP assay was conducted at the CSTl promoter region (Chr20:23,732,257-23,732,507) using the HOXC10 antibody. ChIP-PCR and ChIP-qPCR analysis demonstrated HOXC10 bound to CST1 promoter region (Fig. 5A). Additionally, to indicate whether transcriptional machinery operated by HOXC10 binding to the $C S T 1$ promoter region, a ChIP assay was designed at the transcription start site region of CSTI (Chr20:23,731,473-23,731,614) with phosphorylated RNA pol II antibody. Phosphorylated RNA pol II did bind to the CST1 transcription start site region (Fig. 5B). A ChIP assay was also performed on S100P (another predicted target) promoter regions and TSS regions (Fig. 5C and D). In addition, it was observed that gastric patients with high CSTI expression exhibited decreased recurrence-free survival compared to those with low CST1 expression (Fig. 6A). Combined analysis of CST1 and HOXC10 expression again confirmed that the CST1/HOXC1O high-expression group exhibited worse recurrence-free survival than the CST1/HOXC10 low-expression group (Fig. 6B). These results indicated that overexpression of CST1 mediated by HOXC10 contributes to worse prognosis in gastric cancer patients.

Knockdown of CST1 inhibits gastric cancer progression. Expression of $C S T 1$ wasupregulatedin $\mathrm{HOXC10}$-overexpressing AGS cells (Fig. 4C) and tumor tissues of the TCGA dataset. It was validated that $\mathrm{HOXC10}$ regulated the expression of CSTI by using ChIP-PCR. Gastric cancer patients with both CST1 and HOXC10 overexpression exhibited the poorest survival (Fig. 6B). Thus, the roles of CST1 in gastric cancer progression were investigated using transient knockdown of CST1 in $\mathrm{HOXC10-overexpressing} \mathrm{cells.} \mathrm{The} \mathrm{silencing} \mathrm{of} \mathrm{CST1} \mathrm{was}$ confirmed by RT-qPCR in AGS cells (Fig. 7A). Knockdown of CST1 inhibited cell proliferation (Fig. 7B) and colony formation (Fig. 7C) in AGS cells. CSTI expression was upregulated in $\mathrm{HOXC10-overexpressing} \mathrm{MKN74} \mathrm{cells} \mathrm{and} \mathrm{downregulated}$ in CST1-silencing MKN74 cells (Fig. 7D). Knockdown of 

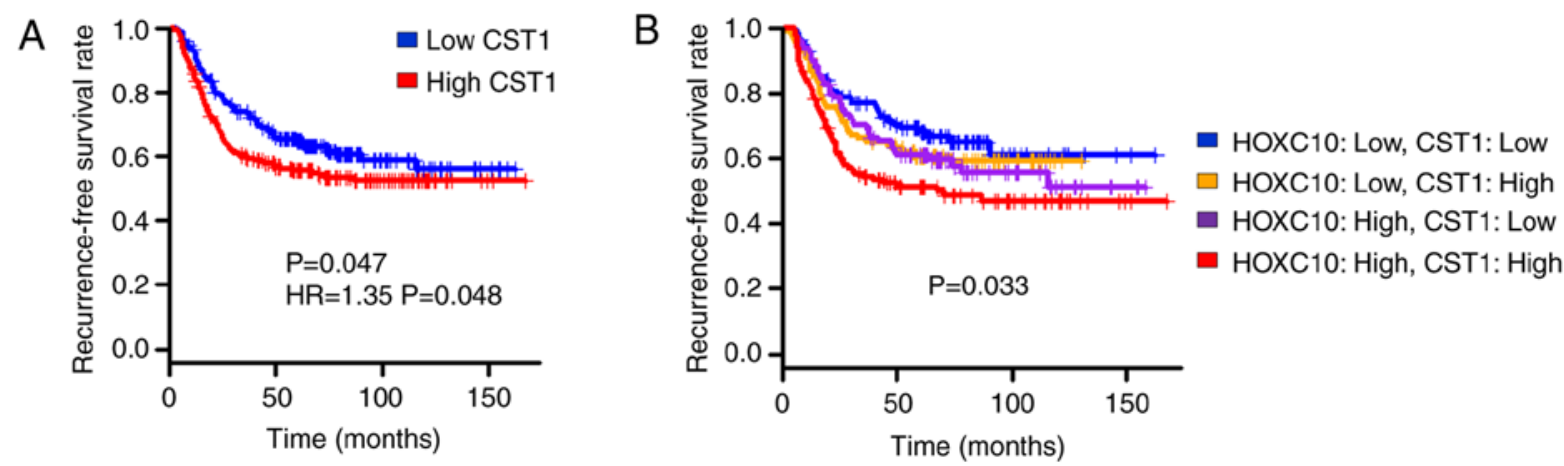

Figure 6. CST1 and HOXC10 expression are associated with clinical outcome. (A) Kaplan-Meier plot of two groups of gastric cancer patients classified by CST1 expression (GSE26253. $\mathrm{n}=432 ; \mathrm{P}=0.047$, log-rank test; Hazard ratio=1.35, $\mathrm{P}=0.048$, cox-regression test). Red, high-expression group, blue, low-expression group. (B) Kaplan-Meier plot of four groups of gastric cancer patients classified by HOXC10 and CST1 expression (GSE26253; n=432; P=0.033. A log-rank test was performed to assess whether the survival curves of the four groups have similar distributions or not). HOXC10, homeodomain-containing gene 10 .
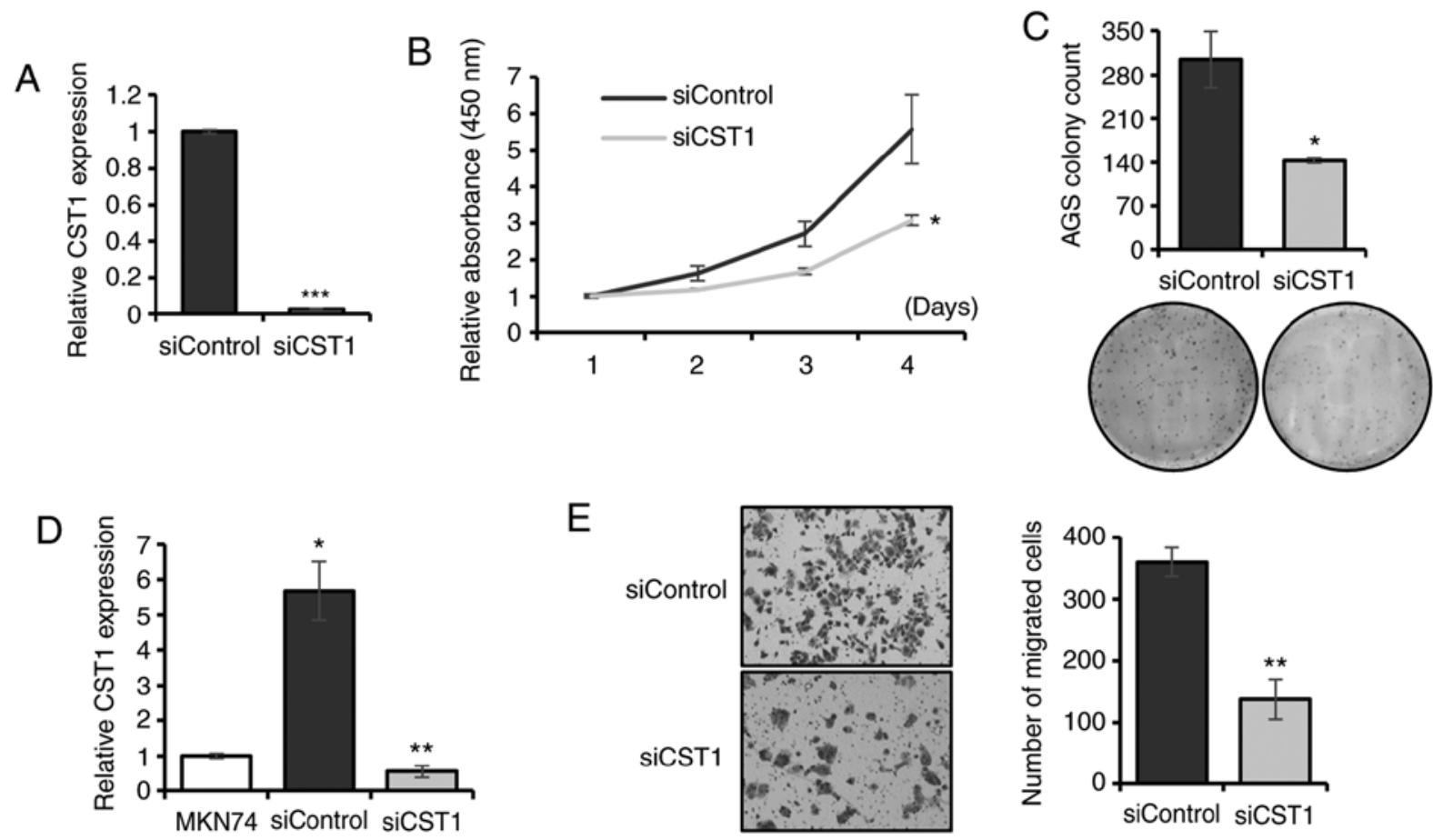

Figure 7. Silencing of CST1 suppresses gastric cancer cell proliferation and migration. (A) RT-qPCR of CST1 in CST1-silencing AGS cells. (B) Proliferation assay (CCK-8) in CST1-silencing AGS cells. (C) Colony formation assay in CST1-silencing AGS cells. (D) RT-qPCR of CST1 in HOXC10-overexpressing (siControl) and $C S T 1$-silencing MKN74 cells. (E) Migration assay in $C S T 1$ silencing MKN74 cells. For all, ${ }^{*} \mathrm{P}<0.05 ;{ }^{* * *} \mathrm{P}<0.01 ;{ }^{* * * *} \mathrm{P}<0.001$, Student's t-test. The error bars represent the mean \pm SD. HOXC10, homeodomain-containing gene 10; CCK-8, Cell Counting Kit-8.

CST1 suppressed the migration ability of MKN74 cells (Fig. 7E). As another downstream target of HOXC10, S10OP was also assessed, and it was revealed that knockdown of $S 100 P$ suppressed cell proliferation and reduced colony size in AGS cells (Fig. S1). CST1 and $S 100 P$ were selected for further validation based on previous studies revealing the role of those two genes in gastric carcinogenesis. For example, CST1 was revealed to increase cell proliferation (25) and S100P to regulate cell proliferation (26) and colony formation (27) in gastric cancer; these two genes exhibited oncogenic roles in other cancers as well (28-33). Altogether, CSTI regulated by HOXC10 contributes to gastric cancer development, and these two genes could be potential prognostic markers for gastric cancer.

\section{Discussion}

Aberrant overexpression of homeodomain-containing gene 10 $(\mathrm{HOXC1O})$ and its role in cancer progression has been reported in many different cancers (10-14). Recently, a few studies have shown that $\mathrm{HOXC1O}$ is overexpressed in gastric cancer and that its overexpression promotes cell growth and migration with activation of MAPK and NF- $\mathrm{BB}$ pathways $(19,20)$. Moreover, HOXC10 expression is correlated with EMT marker genes (SOX10 and FGBPI) (34). We recognized that TMEM41A is upregulated in gastric cancer, especially metastatic and advanced tumors, and contributed to poor prognosis. In vitro and in vivo assay showed that TMEM41A has effects on the migration ability of gastric cancer (35). We investigated 
expression of TMEM4IA with our RNA-sequencing data; however, there were no significant differences in the expression level. This study was associated with other mechanisms in metastasis. However, mechanism of HOXC10 overexpression in gastric cancer are not yet known. In the present study, we demonstrated that hypomethylation of $\mathrm{HOXC10} \mathrm{CpG}$ sites is one mechanism for aberrant overexpression of $\mathrm{HOXC10}$ in gastric cancer. The $\mathrm{CpG}$ sites are located at the $\mathrm{HOXC10}$ first intron and include a promoter retrieved from a eukaryotic promoter database. Although bisulfite sequencing was performed on a partial region of many of the $\mathrm{CpG}$ sites and a few of the tissue samples, the results showed significant correlation between the levels of both DNA methylation and HOXC10 expression.

HOXC10 belongs to the HOX family of transcription factors, which are major regulators of organ development and cellular differentiation during animal development. However, recent studies have shown non-transcriptional interactions for Hox proteins in additional molecular processes, such as mRNA translation, DNA repair and initiation of DNA replication (36). For example, in breast cancer, HOXC10 induces chemotherapy resistance by binding to CDK7 and enhancing homologous recombination DNA repair processes (16). In this regard, it is of interest to reveal how overexpressed $\mathrm{HOXC10}$ exerts its functions in gastric cancer cells, that is, transcriptionally or non-transcriptionally.

In this study, we primarily focused on the role of HOXC10 as a transcriptional regulator. By analyzing RNA-seq and ChIP assays, we identified CST1 as one of the 19 targets genes regulated by $\mathrm{HOXC10}$ in gastric cancer. CST1 is a cysteine protease inhibitor belonging to the cystatin superfamily. Recent studies have shown that CST1 is upregulated and contributes to cancer progression in multiple neoplasms, including gastric (25), breast (31), non-small cell lung cancer (NSCLC) (30), colorectal (33) and pancreatic cancer (32). In colorectal cancer, cathepsin B is associated with invasion of colon cancer cells by extracellular matrix degradation. CST1 attenuates inhibition of cathepsin B by CST3 through binding to CST3 (33), and sustenance of cathepsin B by CST1 promotes cancer development by inhibiting cellular senescence (37). Additionally, CST1 is a mediator of bone metastasis $(38,39)$. However, as mechanisms of CST1 are unclear in gastric cancer, further studies are required. Overexpression of cytokeratin associated protein $(C A P)$ downregulated NF- $\mathrm{B}$ activity and decreased expression of many of its target genes, including CST1 (40). Knockdown of CST1 by miRNA let-7d reduces cell proliferation through phosphorylation of the NF- $\mathrm{B}$ p65 subunit in colorectal cancer (41). Gene-set enrichment analysis using our RNA-seq data revealed that the NF- $\mathrm{KB}$ pathway was activated (Fig. S2A), consistent with a previous study reporting that $\mathrm{HOXC1O}$ activates $\mathrm{NF}-\kappa \mathrm{B}$ in gastric cancer and breast cancer $(16,20)$. We suppose that HOXC10 and CST1 promote cancer progression through the $\mathrm{NF}-\kappa \mathrm{B}$ pathway. TLR4 is one of the NF- $\mathrm{B}$ pathway genes with $\mathrm{HOXC10}$ binding motifs and is overexpressed in cells overexpressing $\mathrm{HOXC10}\left(0.82-\log _{2} \mathrm{FC}\right)$ (Fig. S1B).

In conclusion, $\mathrm{HOXC10}$ expression is upregulated in gastric cancer through DNA demethylation, and $\mathrm{HOXC10}$ overexpression increases proliferation and migration of gastric cancer cells. CST1 was identified as one of the target genes regulated by $\mathrm{HOXC10}$ in gastric cancer. CST1 knockdown represses tumorigenicity of gastric cancer cells. We propose $\mathrm{HOXC1O}$ and $C S T 1$ as useful prognostic markers or therapeutic targets for gastric cancer.

\section{Acknowledgements}

We thank Dr Seong-Min Park for his helpful comments on the manuscript.

\section{Funding}

ThepresentstudywasfundedbygrantsfromtheNationalResearch Foundation of Korea (grant nos. NRF-2017MBA9B5060884 and NRF-2014M3C9A3068554).

\section{Availability of data and materials}

All data generated or analyzed during this study are included in this published article. Gene expression data are available in the GEO databases under the accession no.GSE119196.URL: https:// www.ncbi.nlm.nih.gov/geo/query/acc.cgi?acc=GSE119196.

\section{Authors' contributions}

JK and DHB planned and performed the experiments. JK and SYK wrote the manuscript. JHK collected and analyzed the omics data. KSS selected the patients and collected the clinical samples. YSK contributed to the tissue samples and reviewed the manuscript. SYK supervised the study. All authors read and approved the manuscript and agree to be accountable for all aspects of the research in ensuring that the accuracy or integrity of any part of the work are appropriately investigated and resolved.

\section{Ethics approval and consent to participate}

The present study and all clinical data were approved by the Internal Review Board of the Chungnam National University Hospital (Daejon, Korea). Written informed consent was provided by all the patients.

\section{Patient consent for publication}

Not applicable.

\section{Competing interests}

The authors declare that they have no competing interests.

\section{References}

1. Bray F, Ferlay J, Soerjomataram I, Siegel RL, Torre LA and Jemal A: Global cancer statistics 2018: GLOBOCAN estimates of incidence and mortality worldwide for 36 cancers in 185 countries. CA Cancer J Clin 68: 394-424, 2018.

2. Jung KW, Won YJ, Kong HJ, Lee ES and Community of Population-Based Regional Cancer Registries: Cancer statistics in korea: Incidence, mortality, survival, and prevalence in 2015. Cancer Res Treat 50: 303-316, 2018.

3. Ahn HS, Lee HJ, Yoo MW, Jeong SH, Park DJ, Kim HH, Kim WH, Lee KU and Yang HK: Changes in clinicopathological features and survival after gastrectomy for gastric cancer over a 20-year period. Br J Surg 98: 255-260, 2011. 
4. GASTRIC (Global Advanced/Adjuvant Stomach Tumor Research International Collaboration) Group, Oba K, Paoletti X, Bang YJ, Bleiberg H, Burzykowski T, Fuse N, Michiels S, Morita S, Ohashi Y, et al: Role of chemotherapy for advanced/recurrent gastric cancer: An individual-patient-data meta-analysis. Eur J Cancer 49: 1565-1577, 2013.

5. Kanat O, O'Neil B and Shahda S: Targeted therapy for advanced gastric cancer: A review of current status and future prospects. World J Gastrointest Oncol 7: 401-410, 2015.

6. Yuan DD, Zhu ZX, Zhang X and Liu J: Targeted therapy for gastric cancer: Current status and future directions (Review). Oncol Rep 35: 1245-1254, 2016.

7. Jain D, Nemec S, Luxey M, Gauthier Y, Bemmo A, Balsalobre A and Drouin J: Regulatory integration of Hox factor activity with T-box factors in limb development. Development 145: 159830, 2018.

8. Gabellini D, Colaluca IN, Vodermaier HC, Biamonti G, Giacca M, Falaschi A, Riva S and Peverali FA: Early mitotic degradation of the homeoprotein HOXC10 is potentially linked to cell cycle progression. EMBO J 22: 3715-3724, 2003.

9. Ng Y, Tan SX, Chia SY, Tan HY, Gun SY, Sun L, Hong W and Han W: HOXC10 suppresses browning of white adipose tissues. Exp Mol Med 49: e292, 2017

10. Feng X, Li T, Liu Z, Shi Y and Peng Y: HOXC10 up-regulation contributes to human thyroid cancer and indicates poor survival outcome. Mol Biosyst 11: 2946-2954, 2015.

11. Tang XL, Ding BX, Hua Y, Chen H, Wu T, Chen ZQ and Yuan $\mathrm{CH}$ : HOXC10 Promotes the metastasis of human lung adenocarcinoma and indicates poor survival outcome. Front Physiol 8: 557, 2017.

12. Li S, Zhang W, Wu C, Gao H, Yu J, Wang X, Li B, Jun Z, Zhang W, Zhou P, et al: HOXC10 promotes proliferation and invasion and induces immunosuppressive gene expression in glioma. FEBS J 285: 2278-2291, 2018

13. Xie X, Xiao Y and Huang X: Homeobox C10 knockdown suppresses cell proliferation and promotes cell apoptosis in osteosarcoma cells through regulating caspase 3. Onco Targets Ther 11: 473-482, 2018

14. Ansari KI, Hussain I, Kasiri S and Mandal SS: HOXC10 is overexpressed in breast cancer and transcriptionally regulated by estrogen via involvement of histone methylases MLL3 and MLL4. J Mol Endocrinol 48: 61-75, 2012.

15. Pathiraja TN, Nayak SR, Xi Y, Jiang S, Garee JP, Edwards DP, Lee AV, Chen J, Shea MJ, Santen RJ, et al: Epigenetic reprogramming of HOXC10 in endocrine-resistant breast cancer. Sci Transl Med 6: 229ra241, 2014.

16. Sadik H, Korangath P, Nguyen NK, Gyorffy B, Kumar R, Hedayati M, Teo WW, Park S, Panday H, Munoz TG, et al: HOXC10 expression supports the development of chemotherapy resistance by fine tuning DNA repair in breast cancer cells. Cancer Res 76: 4443-4456, 2016.

17. Sharma S, Kelly TK and Jones PA: Epigenetics in cancer Carcinogenesis 31: 27-36, 2010.

18. Jones PA: Functions of DNA methylation: Islands, start sites, gene bodies and beyond. Nat Rev Genet 13: 484-492, 2012

19. Guo C, Hou J, Ao S, Deng X and Lyu G: HOXC10 up-regulation promotes gastric cancer cell proliferation and metastasis through MAPK pathway. Chin J Cancer Res 29: 572-580, 2017.

20. Yao S, He L, Zhang Y, Ye L, Lai Y, Huang L, Wu L, Wu G and Zhu S: HOXC10 promotes gastric cancer cell invasion and migration via regulation of the NF- $\kappa \mathrm{B}$ pathway. Biochem Biophys Res Commun 501: 628-635, 2018.

21. Lee J, Sohn I, Do IG, Kim KM, Park SH, Park JO, Park YS, Lim HY, Sohn TS, Bae JM, et al: Nanostring-based multigene assay to predict recurrence for gastric cancer patients after surgery. PLoS One 9: e90133, 2014.

22. Livak KJ and Schmittgen TD: Analysis of relative gene expression data using real-time quantitative PCR and the 2(-Delta Delta C(T)) method. Methods 25: 402-408, 2001

23. Dobin A, Davis CA, Schlesinger F, Drenkow J, Zaleski C, Jha S Batut P, Chaisson $M$ and Gingeras TR: STAR: Ultrafast universal RNA-seq aligner. Bioinformatics 29: 15-21, 2013.

24. Zheng J, Ge P, Liu X, Wei J, Wu G and Li X: MiR-136 inhibits gastric cancer-specific peritoneal metastasis by targeting HOXC10. Tumour Biol 39: 1010428317706207, 2017.
25. Choi EH, Kim JT, Kim JH, Kim SY, Song EY, Kim JW, Kim SY, Yeom YI, Kim IH and Lee HG: Upregulation of the cysteine protease inhibitor, cystatin $\mathrm{SN}$, contributes to cell proliferation and cathepsin inhibition in gastric cancer. Clin Chim Acta 406: 45-51, 2009.

26. Ge F, Wang C, Wang $\mathrm{W}$ and $\mathrm{Wu} \mathrm{B}$ : S100P predicts prognosis and drug resistance in gastric cancer. Int J Biol Markers 28: e387-392, 2013.

27. Zhang Q, Hu H, Shi X and Tang W: Knockdown of S100P by lentiviral-mediated RNAi promotes apoptosis and suppresses the colony-formation ability of gastric cancer cells. Oncol Rep 31: 2344-2350, 2014.

28. Li Z, Chen Y, Wang X, Zhang H, Zhang Y, Gao Y, Weng M, Wang L, Liang H, Li M, et al: LASP-1 induces proliferation, metastasis and cell cycle arrest at the $\mathrm{G} 2 / \mathrm{M}$ phase in gallbladder cancer by down-regulating S100P via the PI3K/AKT pathway. Cancer Lett 372: 239-250, 2016.

29. Wu TS, Tan CT, Chang CC, Lin BR, Lai WT, Chen ST, Yen-Ping Kuo M, Rau CL, Jaw FS and Chang HH: B-cell lymphoma/leukemia 10 promotes oral cancer progression through STAT1/ATF4/S100P signaling pathway. Oncogene 36: 5440, 2017.

30. Cao X, Li Y, Luo RZ, Zhang L, Zhang SL, Zeng J, Han YJ and Wen ZS: Expression of cystatin SN significantly correlates with recurrence, metastasis, and survival duration in surgically resected non-small cell lung cancer patients. Sci Rep 5: 8230, 2015.

31. Dai DN, Li Y, Chen B, Du Y, Li SB, Lu SX, Zhao ZP, Zhou AJ, Xue N, Xia TL, et al: Elevated expression of CST1 promotes breast cancer progression and predicts a poor prognosis. J Mol Med (Berl) 95: 873-886, 2017.

32. Jiang J, Liu HL, Liu ZH, Tan SW and Wu B: Identification of cystatin $\mathrm{SN}$ as a novel biomarker for pancreatic cancer. Tumour Biol 36: 3903-3910, 2015.

33. Kim JT, Lee SJ, Kang MA, Park JE, Kim BY, Yoon DY, Yang Y, Lee CH, Yeom YI, Choe YK and Lee HG: Cystatin SN neutralizes the inhibitory effect of cystatin $C$ on cathepsin B activity. Cell Death Dis 4: e974, 2013.

34. Miwa T, Kanda M, Umeda S, Tanaka H, Tanaka C, Kobayashi D, Suenaga M, Hayashi M, Yamada S, Nakayama G, et al: Homeobox C10 influences on the malignant phenotype of gastric cancer cell lines and its elevated expression positively correlates with recurrence and poor survival. Ann Surg Oncol 26: 1535-1543, 2019.

35. Lin B, Xue Y, Qi C, Chen X and Mao W: Expression of transmembrane protein $41 \mathrm{~A}$ is associated with metastasis via the modulation of ecadherin in radically resected gastric cancer. Mol Med Rep 18: 2963-2972, 2018.

36. Rezsohazy R: Non-transcriptional interactions of hox proteins: Inventory, facts, and future directions. Dev Dyn 243: 117-131, 2014.

37. Oh SS, Park S, Lee KW, Madhi H, Park SG, Lee HG, Cho YY, Yoo J and Dong Kim K: Extracellular cystatin SN and cathepsin B prevent cellular senescence by inhibiting abnormal glycogen accumulation. Cell Death Dis 8: e2729, 2017.

38. Blanco MA, LeRoy G, Khan Z, Alečković M, Zee BM, Garcia BA and Kang Y: Global secretome analysis identifies novel mediators of bone metastasis. Cell Res 22: 1339-1355, 2012.

39. Cai X, Luo J, Yang X, Deng H, Zhang J, Li S, Wei H, Yang C, $\mathrm{Xu} \mathrm{L}$, Jin R, et al: In vivo selection for spine-derived highly metastatic lung cancer cells is associated with increased migration, inflammation and decreased adhesion. Oncotarget 6: 22905-22917, 2015.

40. Liu XF, Xiang L, Zhang Y, Becker KG, Bera TK and Pastan I: CAPC negatively regulates NF- $\kappa B$ activation and suppresses tumor growth and metastasis. Oncogene 31: 1673-1682, 2012.

41. Jiang J, Liu HL, Tao L, Lin XY, Yang YD, Tan SW and Wu B: Let7d inhibits colorectal cancer cell proliferation through the CST1/p65 pathway. Int J Oncol 53: 781-790, 2018.

This work is licensed under a Creative Commons Attribution-NonCommercial-NoDerivatives 4.0 International (CC BY-NC-ND 4.0) License. 